EESTI NSV TEADUSTE AKADEEMIA TOIMETISED, 24. KOIDE KEEMIA * GEOLOOGIA. 1975, Nr. 3

ИЗВЕСТИЯ АКАДЕМИИ НАУК ЭСТОНСКОП ССР, ТОМ 24 ХИМИЯ * ГЕОЛОГИЯ. 1975. N 3

Вийве ВИЙРА

УдК $56.016 .3: 551.73 .3(474)$

\title{
НОВЫЙ ВИД SPATHOGNATHODUS ИЗ ЯАНИСКОГО ГОРИЗОНТА ПРИБАЛТИКИ
}

При изучении конодонтов из силурийского разреза скв. Охесааре, расположенной в юго-западной части о. Сааремаа, были обнаружены в небольшом количестве весьма своеобразные спатогнатодусы, которые по наличию большого бокового расширения напоминают платформенные конодонты. Такие спатогнатодусы приурочены к интервалу 256,90294,45 м, сложенному доломитистыми известковыми (местами до глинистых) мергелями в середине яаниского горизонта, т. е. к той части разреза, которая по находкам граптолитов (Monograptus ex. gr. flemingi, $M$. cf. fleming $i$ primus и др.) коррелируется с т. н. флемингиевыми слоями верхнего венлока (Кальо, 1970). Интересующий нас представитель рода Spathognathodus сопровождается довольно бедной ассоциацией конодонтов, представленной немногочисленными экземплярами следующих стержневых видов, имеющих широкое вертикальное распространение: Ozarkodina media Walliser, Spathognathodus inclinatus inclinatus (Rhodes), Trichonodella excavata (Branson et Mehl), Ligonodina sp., Synprioniodina sp., Acodus sp., Panderodus sp., «Oneotodus» sp. (см. табл., фиг. 5-17; рис., фиг. 8-20). К этому списку можно добавить еще Hindeodella equidentata Rhodes и Neoprioniodus excavatus (Branson et Mehl), ибо они встречаются вместе с описанным ниже Spathognathodus в разрезе скв. Укмярге (гл. $416 м$ ) Литовской ССР.

Кроме конодонтов, в нерастворимом остатке проб найдены мелкие беззамковые брахиоподы, обломки граптолитов и сколекодонты.

Описанный материал хранится в фондах Института геологии $\mathrm{AH}$ ЭССР в Таллине.

\section{Род Spathognathodus Branson et Mehl, 1941}

Т и по во й вид. Spathodus primus Branson et Mehl, 1933. Северная Америка, силур, формация Бейнбридж.

\section{Spathognathodus corpulentus sp. nov.}

Табл., фиг. $1-4$; рис., фиг. $1-7$

Г ол о ти п. Правый экземпляр Cn 841 ; табл., фиг.1; рис., фиг. $1, a-c$; яаниский горизонт $\left(\mathrm{J}_{1}\right)$, разрез скв. Охесааре, гл. 294,0-294,45 м.

Д и а г о з. Крупный листообразный конодонт с большим базальным расширением в задней части листа и боковым зубчатым валиком посередине его внешней стороны. Часть зубчиков главного зубчатого ряда и бокового валика бугорчатые. Широко открытая базальная полость занимает всю задне-нижнюю часть конодонта.

О п и с ание. Крупные конодонты с листообразной узкой передней и расширенной, платформообразной задней частью. Вид сбоку типично 
спатогнатодусовый, особенно с внутренней боковой стороны, ибо с внешней стороны расположен боковой валик, обычно отсутствующий у представителей рода Spathognathodus. Благодаря большим размерам базального расширения сверху конодонт больше похож на платформенные конодонты, чем на листообразные.

Лист конодонта образуется высоким основанием и зубчатым рядом в его верхней части (примерно в верхней трети). Гребень листа ровный, лишь самые передние зубчики могут незначительно выступать над остальными. Нижний край листа в середине конодонта имеет дугообразный прогиб, а к переднему и заднему краям слегка поднимается. Обычно конодонт ровно вытянут, лишь на самом заднем конце, где зубчатый ряд загибается внутрь, а на выпуклой внешней стороне проходит боковой валик, наблюдается изогнутость. В передней части лист узкий; примерно в середине конодонта основание довольно резко расширяется, переходя в сильно вздутое боковое расширение, а верхняя зубчатая часть над этим широким основанием утолщается.

Зубчики на гребне листа при виде сбоку вертикальные, плотнопримыкающие, слившиеся, тупые; только на переднем конце они тонкие, с заостренными верхушками. По мере удаления от переднего края и приближения к заднему зубчики утолщаются, верхушки становятся менее острыми и постепенно принимают бугорчатый облик. Некоторые зубчики (обычно перед ответвлением бокового валика) могут быть представлены парными бугорчатыми возвышениями с пережимами между ними. Ближе к заднему краю толщина зубчиков опять немного уменьшается.

Боковой валик отходит от зубчатого ряда листа в его задней части, примерно на расстоянии четырех-шести зубчиков от края. Он расположен в середине или ближе к задней части внешней стороны бокового расширения. Зубчики валика бугорчатые, их тупые верхушки находятся примерно на одном уровне с верхушками зубчиков главного ряда. Количество зубчиков на валике (и тем самым длина валика) может меняться; у наших экземпляров их не более шести-семи.

Боковое расширение обычно охватывает всю заднюю половину основания, расширяясь от базальной части зубчатого ряда и бокового валика на обе стороны листа. Размеры расширения обычно больше или равны половине длины конодонта. Поверхность его на участках между зубчатым рядом и боковым валиком гладная, без какой-либо скульптуры, слегка выпуклая, понижающаяся к нижнему краю. При виде сверху расширение грубо угловато-округлое, со слегка волнистым краем. Установить точный контур почти невозможно, так как нижний край очень тонкий и поэтому часто обломан.

Фиг. 1-7. Spathognathodus corpulentus sp. п. 1 - голотип, правый экземпляр Cn 841 , $2-7$ - левые $(3,5,7)$ и правые $(2,4,6)$ экземпляры Cn $842-\mathrm{Cn} 847$.

$a-$ вид с внешней боковой стороны, в - вид сверху, $c-$ вид снизу.

Фиг. 8, 9. Ligonodina sp. Правый и левый экземпляры Cn 848 и $\mathrm{Cn} 849$.

Фиг. 10. Trichonodella sp. Экземпляр Cn 850.

Фиг. 11-13. Ozarkodina media Walliser. Экземпляры Cn 851 - Cn 853.

Фиг. 14, 15. Spathognathodus inclinatus inclinatus (Rhodes). Экземпляры $\mathrm{Cn} 854$ и Cn 855.

Фиг. 16. Hindeodella equidentata Rhodes. Экземпляр Cn 856.

Фиг. 17. Trichonodella excavata (Branson et Mehl). Экземпляр Cn 857.

Фиг. 18. Neoprioniodus excavatus (Branson et Mehl). Экземпляр Cn 858.

Фиг. 19, 20. «Oneotodus» sp. Экземпляры Cn 859 и Cn 860.

$1-4,6-9,11,13,19,20-$ скв. Oxесаape: $1-4,8,9,19-$ гл. $294,0-294,45 \mu ; 6,13$, 20 - гл. $277,15-277,5 м ; 7-$ гл. $256,9-257,25 м ; 11-$ гл. $284,5-285,0$ м.

$5,10,12,14-18-$ скв. Укмярге, гл. $416 м$.

Увел, $\times 60$. 

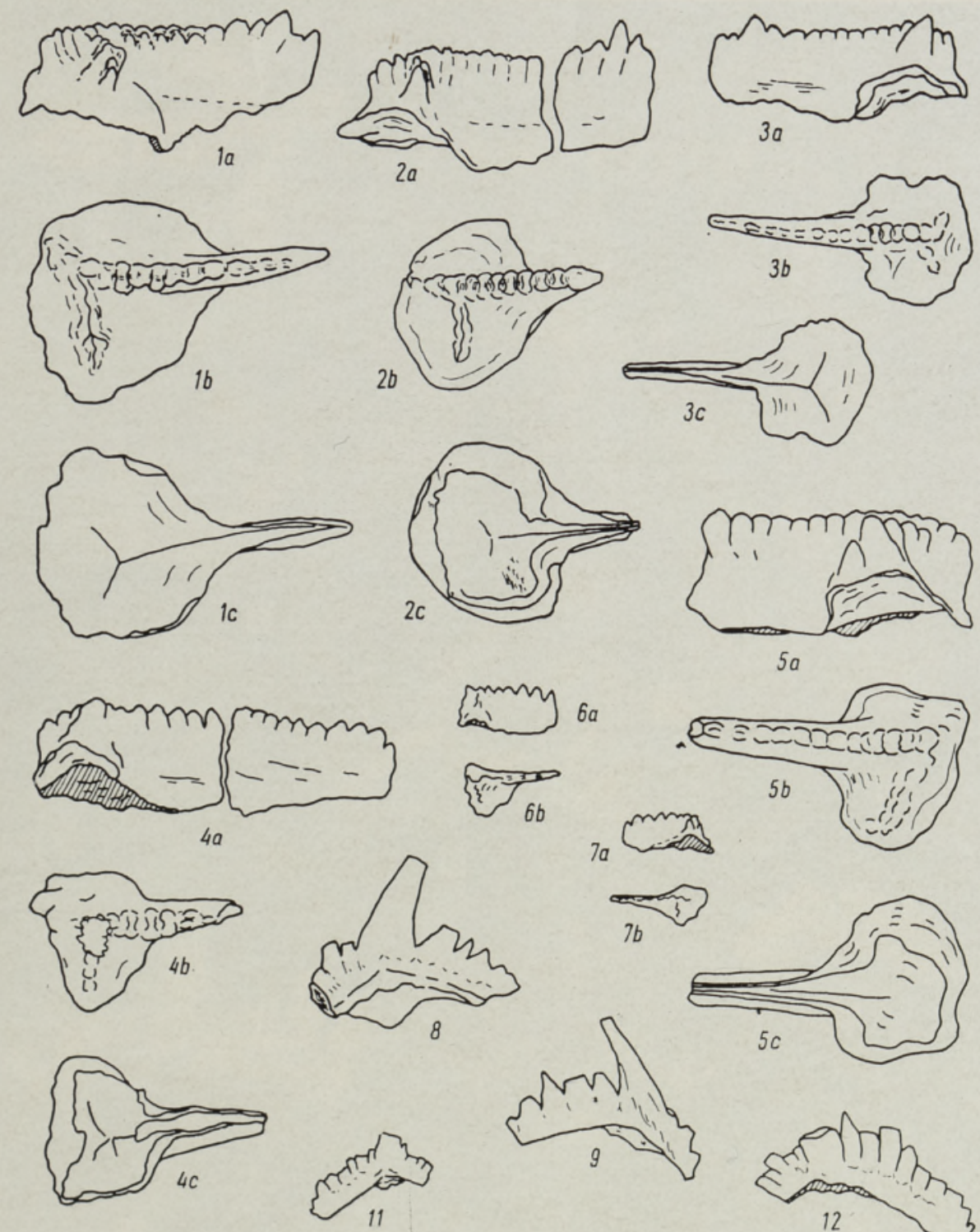

${ }_{7 a} \mathrm{c}$
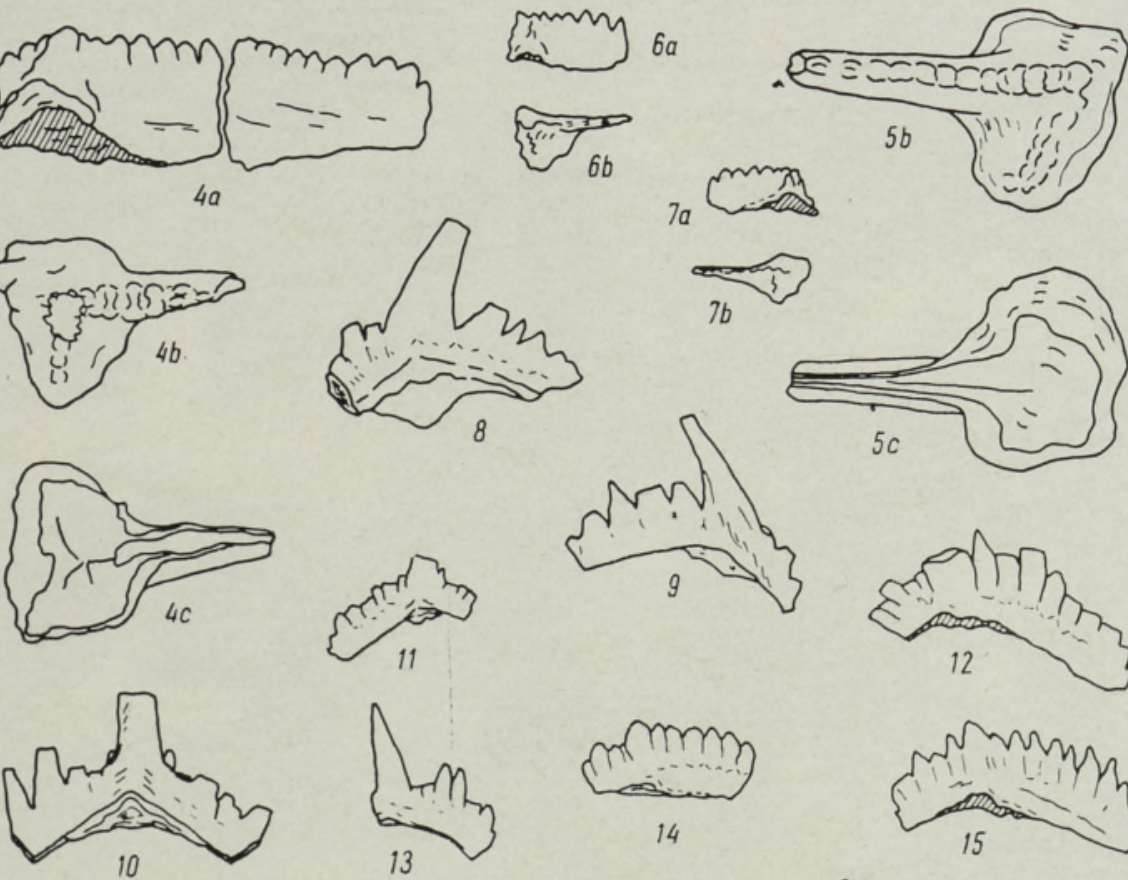

$\frac{\text { Amm thm? }}{16}$
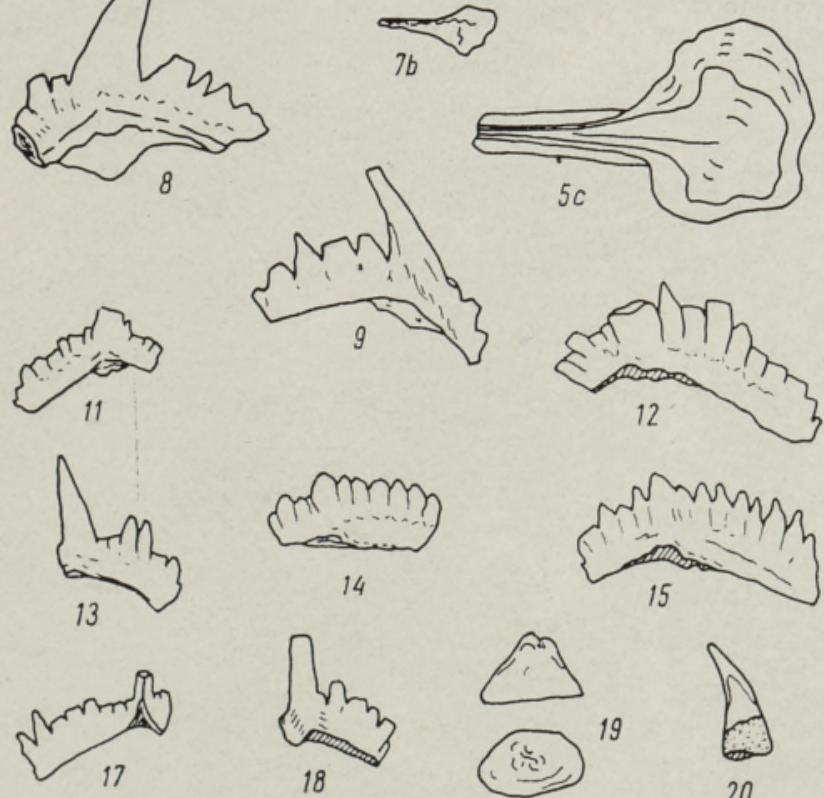

17

18

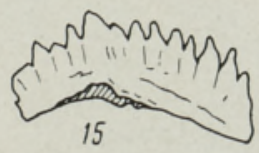

(iv) $^{19}$ 


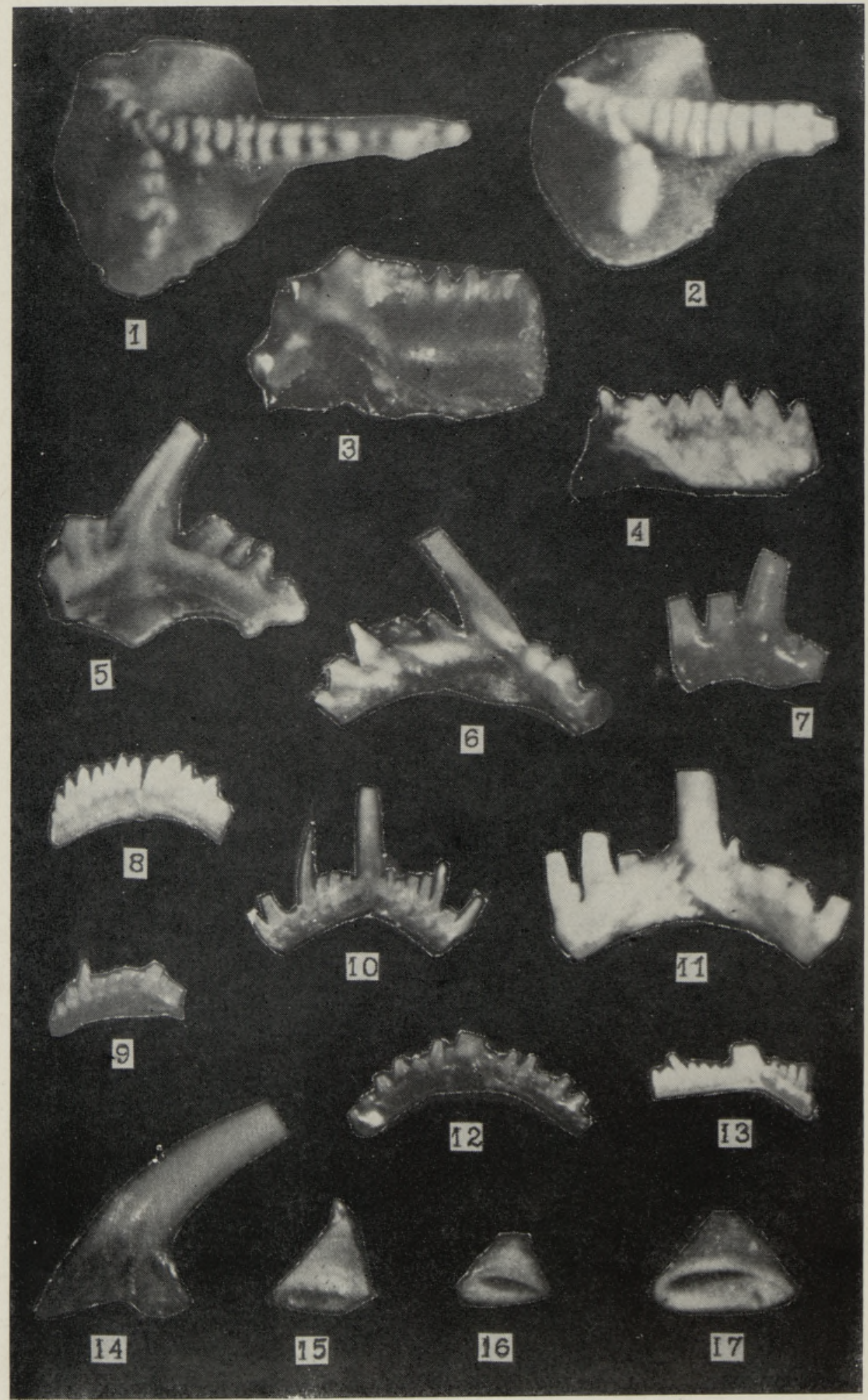


На нижней стороне под боковым расширением находится большая базальная полость, которая плоскоконически вдается в конодонт. Верхушка базальной полости расположена примерно под зубчатым рядом на месте ответвления бокового валика. Поверхность полости не совсем ровная, более глубокие участки находятся под рядом зубчиков (от верхушки по обе стороны) и под валиком. Контур базальной полости повторяет контур края базального расширения. Приблизительно на середине длинной оси листа полость резко сужается и постепенно принимает вид желобка, идущего до конца переднего края листа.

У некоторых экземпляров сохранилось базальное заполнение, которое в виде плоскоконического тела занимает почти всю базальную полость, оставляя свободными лишь края. Нижняя поверхность заполнения слегка вогнутая. У экземпляров из разреза скв. Охесааре заполнение имеет темный цвет, а у экземпляров из разреза скв. Укмярге - светлый.

И з м ен ч и в ост ь. 1. Правые экземпляры отличаются от левых относительно бо́льшими размерами бокового расширения и базальной полости, а также более перпендикулярным положением бокового валика по отношению к главному зубчатому ряду.

2. Изменчивы длина бокового валика, длина свободного листа, количество бугорчатых зубчиков и зубчиков с пережимами.

3. Изменчива форма базального расширения, которое при обычном угловато-округлом очертании иногда имеет треугольный облик (особенно у маленьких экземпляров).

4. Большие (взрослые) и маленькие (юные) экземпляры отличаются довольно значительно. Так, юные формы имеют относительно небольшое расширение, минимальное на внутренней стороне, короткий боковой валик на внешней стороне и тонкие острые зубчики, не переходящие в бугорки.

С р а внение. Описываемый вид по общей форме листа, большим размерам базального расширения и наличию бокового валика очень походит на Spathognathodus n. sp., отличаясь от него лишь бугорчатым характером зубчиков. Единственный экземпляр этого вида из Рейнских Сланцевых Гор (Гиссен, зона sagitta) описал О. Валлизер (Walliser, 1964; табл. 22, фиг. 8). Там же он обнаружил еще следующие виды: Spathognathodus sagitta rhenanus Walliser, Ozarkodina edithae Walliser, Neoprioniodus bicurvatoides Walliser, Synprioniodina silurica Walliser, Lonchodina walliseri Ziegler, Trichonodella excavata, Ligonodina cf. salopia Rhodes. Названная ассоциация конодонтов известна в Әстонии в разрезе скв. Охесааре примерно в 100 м выше слоев с Spathognathodus corpulentus sp. n. - в пограничных слоях яагарахуского и роотсикюлаского горизонтов (Вийра, в печати).

Фиг. 1-4. Spathognathodus corpulentus sp. n. 1 - голотип, правый экземпляр Cn 841 , 2-4 - правые экземпляры Cn $842, \mathrm{Cn} 844$ и $\mathrm{Cn} 846 ; 1,2$ - вид сверху, $3,4-$ вид сбоку.

Фиг. 5, 6. Ligonodina sp. Экземпляры Cn 848 и Cn 849.

Фиг. 7. Synprioniodina sp. Экземпляр Cn 861.

Фиг. 8, 9. Spathognathodus inclinatus inclinatus (Rhodes). Экземпляры Cn 855 и Cn 862.

Фиг. 10. Trichonodella excavata (Branson et Mehl). Экземпляр $\mathrm{Cn} 863$.

Фиг. 11. Trichonodella sp. Экземпляр Cn 850.

Фиг. 12. Ozarkodina media Walliser. Экземпляр Cn 864.

Фиг. 13. Hindeodella equidentata Rhodes. Экземпляр Cn 856.

Фиг. 14. Acodus sp. Экземпляр Cn 865.

Фиг. 15-17. «Oneotodus» sp. Экземпляры Cn 866 - Cn 868.

$1-7,9,10,12,14-17-$ скв. Oxесаape: $1-3,5,6,17-$ гл. $294,0-294,45 \mu ; 4-$ гл. $277,15-277,5$ м; 7, 9, 12, 14 - гл. $290,8-291,1$ м; 10, 15, 16 - гл. $284,5-285,0$ м. $8,11,13-$ скв. Укмярге, гл. $416 \mu$.

Увел. $\times 65$ (фиг. 8, 9, 13); $\times 100$ (фиг. $1-3,5-7,10-12,15-17) ; \times 160$ (фнг. 4, 14). 
До некоторой степени $S$. corpulentus sp. n. приближается к группе спатогнатодусов с большой базальной полостью (S. crispus Walliser, $S$. snajdri Walliser, $S$. ranuliformis Walliser и др.), но отличается от них наличием бокового валика, иным характером зубчатости и иным расположением базальной полости.

Геологический возраст и распространение. Венлок Прибалтики. Средняя часть яаниского горизонта $\left(\mathrm{J}_{1}\right)$ Эстонии.

$M$ а те р и а л. Разрез скв. Охесааре: три правых и один левый экземпляр с гл. 294,0-294,45 м; один правый экземпляр с гл. 290,80-291,10 м; один правый экземпляр с гл. 277,15-277,50 м; один левый экземпляр с гл. $256,90-257,25$ м; один левый экземпляр с гл. 416 м скв. Укмярге.

\section{Л ИТ Е РА Т У РА}

В и й р а В. Я. Состав и распространение конодонтов в силуре Прибалтики (скв. Охеcaаре, Кункояй, Укмярге и др.). В сб.: Фауна, фации и стратиграфия силуря Прибалтики, Таллин (в печати).

К а ль о Д. Л. (ред.). 1970. Силур Эстонии. Таллин.

W a 11 is er O. H. 1964. Conodonten des Silurs Abh. Hess. Landesamt. Bodenforsch, Bd. 41 .

\section{Ннститут геологии \\ Академии наук Эстонской ССР \\ Поступнла в редакцию \\ $14 / \mathrm{I} 1975$}

Viive VIIRA

\section{SPATHOGNATHODUS'e UUS LIIK BALTIKUMI JAANI LADEMES}

Artiklis kirjeldatud uus konodondiliik Spathognathodus corpulentus on leitud Ohesaare puursüdamiku jaani lademe merglitest, mida graptoliidileidude pōhjal korreleeritakse ülemuenloki flemingi kihtidega.

\section{Viive VIIRA}

\section{A NEW SPECIES OF SPATHOGNATHODUS FROM THE JAANI STAGE OF THE EAST BALTIC}

The new species Spathognathodus corpulentus is described from the magnesian calcareous marl of the Jaani Stage (Ohesaare boring). It comes from the interval corresponding to the Monograptus flemingi beds.

Spathognathodus corpulentus sp. $\mathrm{n}$.

(Pl., Figs. 1-4; Text-fig., 1-7)

Holotype. Dextral specimen $\mathrm{Cn} 841$, Jaani Stage $\left(\mathrm{J}_{1}\right)$, Ohesaare boring, depth $294.0-294.45 \mathrm{~m}$, South-East Estonia, Pl., Fig. 1; Text-fig., 1, a-c.

$\mathrm{Di}$ a $\mathrm{n}$ os is. A blade-like conodont with extensively flared lips at the posterior end. The oral surface of the outer lip is ornamented by a denticulated ridge or row of nodes merging with the denticulated posterior blade. A number of the denticles of the blade are paired, rounded or node-like. The basal cavity is widely open in the posterior part of the unit. 